\title{
СЕСТРИНСКИЙ УХОД ЗА БОЛЬНЫМ С ДИАБЕТИЧЕСКАЯ СТОПА
}

\section{ОРИГИНАЛЬНАЯ СТАТЬЯ}

CUNHA, Amanda Priscilla da ${ }^{1}$

CUNHA, Amanda Priscilla da. Сестринский уход за больным с диабетическая стопа. Revista Científica Multidisciplinar Núcleo do Conhecimento. Год. 06, Изготовить. 12, Vol. 12, с. 111-126. Декабрь 2021 года. ISSN: 2448-0959, Ссылка доступа:

https://www.nucleodoconhecimento.com.br/здравоохранение/диабетическаястопа, DOI: 10.32749/nucleodoconhecimento.com.br/ru/105167

\section{СВОДКА}

Введение: Диабетическая стопа, также называемая многогранным патофизиологическим состоянием, характеризуется поражениями, которые возникают из стоп человека с сахарным диабетом без адекватного лечения и специфического ухода. Подсчитано, что заболеваемость диабетической язвой стопы достигает 6,3\% больных сахарным диабетом и ее распространенность приближается к 10\%, а наибольшими жертвами являются люди с низким социально-экономическим статусом. С учетом этих доказательств работа основана на следующем проблемном вопросе: Какую помощь развивает медсестры у пациентов с диабетическая стопа? Общая цель: Доказать уход за диабетическая стопа, связанный с практикой медсестер. Методология: Интегративный обзор был проведен в Специализированной библиографрической базе данных по сестринскому делу (BDENF), латиноамериканской и карибской литературе по наукам о здоровье (LILACS) и Научной электронной библиотеке онлайн (SCIELO), в результате чего было подготовлено семь статей. Результаты: Исследования показали, как

\footnotetext{
${ }^{1}$ Магистр в области управления больницами и систем здравоохранения, медсестра полная степень в области сестринского дела. ORCID: 000-0001-5456-1848.
}

RC: 105167

Доступно в:

https://www.nucleodoconhecimento.com.br/здравоохранение/диабетическая-стопа 
осуществляется уход за медсестрами с диабетическая стопа, санитарное просвещение, непрерывное и постоянное образование, методы оценки диабетическая стопа, которые включают фризические осмотры и самообслуживание пациентов с диабетической стопой. Подчеркивается, что этот уход должен осуществляться в приоритетном порядке медсестрами, поскольку медсестры имеют конкретную и квалифицированную помощь пациенту в своих основных атрибутах. Вывод: Таким образом, делается вывод о том, что исследование выявило несколько фрорм ухода, предоставляемого медсестрами, и что все эти формы важны для непрерывности лечения и профилактики осложнений, однако медсестра должна быть профессионалом, который ценит качество своего ухода, основываясь на теоретических концепциях, которые приводят к частому обучению.

Ключевые слова: уход за пациентом, сахарный диабет, диабетическая стопа.

\section{1. ВВЕДЕНИЕ}

Сахарный диабет (СД) - это заболевание, развивающееся в эндокринной системе и / или хроническое метаболическое расстройство, представляющее серьезную всемирную проблему со здоровьем и имеющее в качестве своей основной характеристики гипергликемию, достигающую уровня глюкозы в крови более 126 мг / дл при голодании или >200 мг / дл на постпрандиальной стадии, и которое, возможно, было связано с резистентностью к инсулину, и которое, возможно, было связано с резистентностью к инсулину, неадекватная секреция инсулина или чрезмерная секреция глюкагона (ASCHNER et al., 2016).

Поэтому гипергликемия вызывает полную или частичную неспособность к выработке инсулина, по данным Бразильского Диабетического Общества (SBD), American Diabetes Association (ADA) и Всемирной организации здравоохранения (BO3) СД делится на четыре группы: сахарный диабет 1 типа, сахарный диабет 2 типа, гестационный сахарный диабет и другие специфические типы диабета (OMS, 1999; SBD, 2017; ADA 2017). 
SBD описывает фракторы риска развития СД, которые приводятся следующим образом: диагностика преддиабета - снижение толерантности к глюкозе или изменение глюкозы натощак; гипертония; гиперхолестеринемия или изменения нормы триглицеридов в крови; избыточный вес и ожирение, особенно если жир сосредоточен вокруг талии; семейная история; малыш весом более четырех килограммов или гестационный диабет; синдром поликистозных яичников; диагностика некоторых психических расстройств, таких как шизофрения, депрессия, биполярное расстройство и применение психотропных препаратов; другие (SBD, 2018).

Потому что это заболевание, которое поражает примерно 3\% населения мира и с приблизительной распространенностью 6,2\% населения Бразилия, то же самое увеличивается с учетом старения населения (MUZY et al., 2021), СД вызвал натяжение в государственной казне, кроме того, что позволяет высокие затраты на лечение его осложнений, таких как: диабетическая стопа, сердечнососудистые заболевания, ампутация и другие. Примечательно, что фрармакологическое лечение добивается прогресса в борьбе с СД, однако санитарное просвещение как форма профилактики должно передаваться населению в целом индивидуально или группово, подчеркивая проблему заболевания и его вред здоровью (SILVA, 2018).

Что касается осложнений СД, то диабетическая стопа также называют ее многогранным патологическая фризиология состоянием, характеризующимся поражениями, возникающими у ног человека с сахарным диабетом от нейропатии в 90\% случаев, при которых преобладают заболевания и деформации периферических сосудов (CUBAS et al., 2017).

De Sousa Mendonça; Moraes; Moura (2017) описывает, что существующие поражения в диабетическая стопа происходят от комбинации двух или более фракторов риска, которые могут быть связаны с внутренними травмами, такими как внешние, связанные с периферической невропатией, вызывающей потерю чувствительности, способствуя риску порезов; Заболевание периферических 
сосудов, возникающее в результате снижения кровотока в нижних конечностях и биомеханических изменений, возникающих при ограничении движений суставов стопы и голеностопного суставов.

Подсчитано, что заболеваемость диабетическая язвой стопа достигает 6,3\% больных сахарным диабетом и ее распространенность приближается к 10\%, а наибольшими жертвами являются люди с низким социально-экономическим статусом. Ампутация диабетическая стопа является еще одной проблемой, и во всем мире каждые три минуты человеку ампутируют конечность из-за СД (ARRUDA et al., 2021).

Надлежащее управление фракторами, вовлеченными в этиологию существующего поражения диабетической стопы, становится эффрективным, когда оно осуществляется медсестрой, для чего она должна иметь возможность и квалификацию для проведения сестринской консультации с целью выявления дерматологических, костно-мышечных, сосудистые изменения и неврологические при диабетической стопе (FÉLIX et al., 2021).

Поэтому уход за диабетической стопой становится очень важным в рамках общественного здравоохранения, и медсестра, как профессионал, который имеет в своем распоряжении уход за пациентом, должна быть внимательной и квалифицированной в отношении новых форм лечения для уменьшения ампутаций. Перед лицом этого сценария тревожных показателей важно наблюдать, как медсестры расположены в практиках по уходу за диабетическая стопа.

Учитывая эти доказательства, которые включают в себя тревожные цифры в отношении диабетическая стопа, работа основана на следующем проблемном вопросе: Какую помощь развивают медсестры у пациентов с диабетическая стопа?

Исследование, о котором идет речь, направлено на то, чтобы доказать уход за диабетическая стопа, связанный с практикой медсестер.

RC: 105167

Доступно в:

https://www.nucleodoconhecimento.com.br/здравоохранение/диабетическая-стопа 


\section{2. МЕТОДОЛОГИЯ}

Для данного исследования был проведен интегративный обзор литературы. Согласно Mendes; Silveira и Galvão (2019), метод интегративного обзора разработан в соответствии с четко определенными шагами; к ним относятся: определение темы и выбор северного вопроса; установление критериев включения и исключения; выявление предварительно отобранных и отобранных исследований; категоризация отдельных исследований; анализ и интерпретация результатов и представление резюме обзора.

Первым шагом интегративного обзора является северный вопрос, который приводит к перечисленным темам и целям. Поэтому вопрос, который возникает в этой статье: какую заботу развивают медсестры у пациентов с диабетическая стопа?

Для установления критериев включения были использованы: статьи, опубликованные и доступные для чтения, так как предмет отражает медсестру в своих атрибуциях, была выбрана База данных BDENF, LILACS и SCIELO, временное разграничение было в 2016-2020 годах, то есть в последние пять лет, и для этого включения был выбран португальский язык.

Для исключения были удалены критерии: статьи, имеющие двуличность, неполные статьи, материалы конференции, тексты мнений, редакционные статьи и письма к читателю, обзорные статьи, диссертации, полные тексты, но не относящиеся к теме.

Период сбора данных соответствовал месяцу сентябрь 2021 года. Национальными дескрипторами были названы: «уход за больными», «диабетическая стопа», «Медсестра», «сахарный диабет». Логический оператор and использовался для связывания дескрипторов в стратегии поиска на платформе базы данных. 
Для отбора отобранных и предварительно отобранных исследований было произведено тщательное прочтение названий и рефератов найденных статей, а затем более полное прочтение по всей статье, заглядывая в ее результаты для выявления для достижения цели, предложенной в данной статье.

Было проведено два поиска, в первом использовалась следующая стратегия поиска: уход за больным and диабетическая стопа и сахарный диабет, при этой стратегии было найдено 186 статей. После использования фильтров: полный и доступный текст, база данных, португальский язык и временное разграничение за последние пять лет, 24 статьи остались для получения права на участие. Второй поиск проводился со следующей стратегией: медсестра and диабетическая стопа нашли 95 статей. После использования фильтров 11 статей остались на соответствие требованиям.

Исследования были классифицированы по синоптической картине, а анализ и представление результатов были проведены после категоризации, которая определила и определила значение ядер исследований, и что из тематического анализа Minayo (2012) среди найденных авторов была дискуссия.

Для синтеза знаний был проведен анализ ограничений, репрезентативности исследования для сообщества в целом (актуальности) и будущих исследований, выявленных в ходе данной статьи. Все продукты, используемые в этом исследовании, строго соответствуют стандартам Бразильской ассоциации технических стандартов (ABNT).

\section{3. РЕЗУЛЬТАТЫ И ДИСКУССИИ}

Остальные статьи, отвечающие критериям для обеих стратегий, составили в общей сложности 35 статей. Первоначально обзорные статьи, работы по окончанию курса, письма к читателю, отчеты об опыте, тематические исследования, дубликаты статей были удалены и что в их названиях, 
рефератах и чтении в полном объеме не привело медсестру и его заботу в качестве темы к теме, таким образом, оставив 07 статей для этого обзора.

Для лучшей иллюстрации полученных результатов в следующую таблицу будет включена характеристика отобранных исследований. Данные относятся к: названию статьи, году публикации, базе данных, журналу, местоположению, цели и результатам.

Таблица 1. Статьи, найденные в базе данных BDENF, LILACS и SCIELO по сестринскому уходу за пациентами с диабетической стопой.

\begin{tabular}{|c|c|c|c|c|c|}
\hline $\begin{array}{l}\text { Название/ } \\
\text { Год } \\
\text { издания }\end{array}$ & $\begin{array}{l}\text { база } \\
\text { данн } \\
\text { ых }\end{array}$ & $\begin{array}{l}\text { периодиче } \\
\text { ский }\end{array}$ & Цель & Местный & Выводы \\
\hline $\begin{array}{l}\text { Conhecim } \\
\text { ento do } \\
\text { enfermeiro } \\
\text { acerca dos } \\
\text { cuidados } \\
\text { com o pé } \\
\text { diabético } \\
2019\end{array}$ & $\begin{array}{l}\text { BDE } \\
\text { NF }\end{array}$ & $\begin{array}{l}\text { Rev. } \\
\text { enferm. } \\
\text { UFPE on } \\
\text { line }\end{array}$ & $\begin{array}{l}\text { Понимание } \\
\text { знаний } \\
\text { медсестры о } \\
\text { лечении } \\
\text { диабетической } \\
\text { стопы } \\
\text { первичной } \\
\text { медико- } \\
\text { санитарной } \\
\text { помощи }\end{array}$ & $\begin{array}{l}\text { Стратегия } \\
\text { охраны } \\
\text { здоровья } \\
\text { семьи/ESF }\end{array}$ & $\begin{array}{l}\text { Периодическ } \\
\text { и проводить } \\
\text { физикальное } \\
\text { обследовани } \\
\text { е стоп у } \\
\text { диабетиков; } \\
\text { Использован } \\
\text { ие } \\
\text { инструментов } \\
\text { для оценки } \\
\text { диабетическо } \\
\text { й стопы } \\
\text { Уход за собой } \\
\text { у ног }\end{array}$ \\
\hline $\begin{array}{l}\text { Riscos } \\
\text { associado } \\
\text { s à }\end{array}$ & $\begin{array}{l}\text { LILA } \\
\text { CS/ } \\
\text { BDE }\end{array}$ & $\begin{array}{l}\text { Rev. } \\
\text { gaúch. } \\
\text { enferm }\end{array}$ & $\begin{array}{ll}\text { Определите } & \text { у } \\
\text { пациентов } & \text { с } \\
\text { диабетом } & 2\end{array}$ & $\begin{array}{l}\text { Образовате } \\
\text { льная } \\
\text { программа }\end{array}$ & $\begin{array}{l}\text { Санитарное } \\
\text { просвещение } \\
\text { по гигиене }\end{array}$ \\
\hline
\end{tabular}


REVISTA CIENTÍFICA MULTIDISCIPLINAR NÚCLEO DO CONHECIMENTO ISSN: 2448-0959

https://www.nucleodoconhecimento.com.br

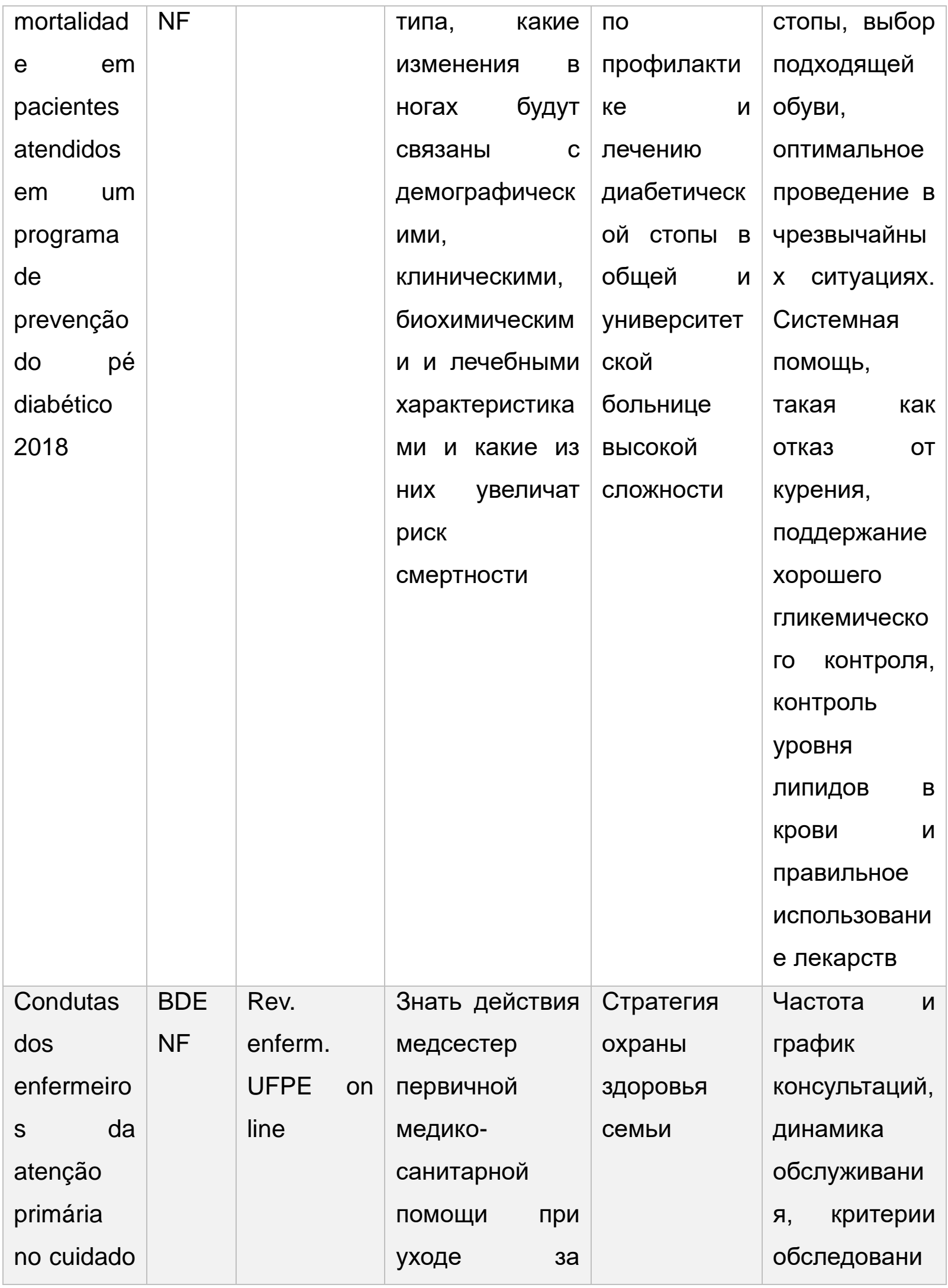

RC: 105167

Доступно в:

https://www.nucleodoconhecimento.com.br/здравоохранение/диабетическая-стопа 


\begin{tabular}{|c|c|c|c|c|c|}
\hline $\begin{array}{l}\text { a pessoas } \\
\text { com pé } \\
\text { diabético } \\
2017\end{array}$ & & & $\begin{array}{l}\text { людьми с } \\
\text { сахарный } \\
\text { диабет (СД), } \\
\text { связанными с } \\
\text { диабетической } \\
\text { стопой }\end{array}$ & & $\begin{array}{l}\text { я стоп, } \\
\text { самообслужи } \\
\text { вание }\end{array}$ \\
\hline $\begin{array}{l}\text { Ações do } \\
\text { enfermeiro } \\
\text { na } \\
\text { prevenção } \\
\text { do pé } \\
\text { diabético: } \\
\text { o olhar da } \\
\text { pessoa } \\
\text { com } \\
\text { diabetes } \\
\text { mellitus } \\
2017\end{array}$ & $\begin{array}{l}\text { LILA } \\
\text { CS/ } \\
\text { BDE } \\
\text { NF }\end{array}$ & $\begin{array}{l}\text { Rev. } \\
\text { Pesqui. } \\
\text { (Univ. Fed. } \\
\text { Estado Rio } \\
\text { J., Online) }\end{array}$ & $\begin{array}{l}\text { Исследовать } \\
\text { действия, } \\
\text { проводимые } \\
\text { медсестрами в } \\
\text { профилактике } \\
\text { диабетической } \\
\text { стопы с точки } \\
\text { зрения } \\
\text { человека с СД. }\end{array}$ & $\begin{array}{l}\text { Проект } \\
\text { расширения } \\
\text { университет } \\
\text { a }\end{array}$ & $\begin{array}{l}\text { Конкретные } \\
\text { действия, } \\
\text { которые } \\
\text { должным } \\
\text { образом } \\
\text { включают } \\
\text { осмотр } \\
\text { стопы, } \\
\text { коммуникатив } \\
\text { ный диалог, } \\
\text { санитарное } \\
\text { просвещение. }\end{array}$ \\
\hline $\begin{array}{l}\text { Alterações } \\
\text { nos pés do } \\
\text { idoso } \\
\text { hospitaliza } \\
\text { do: um } \\
\text { olhar } \\
\text { cuidadoso } \\
\text { da } \\
\text { enfermage } \\
\text { m } \\
2017\end{array}$ & $\begin{array}{l}\text { LILA } \\
\text { CS/ } \\
\text { BDE } \\
\text { NF }\end{array}$ & $\begin{array}{l}\text { Esc. Anna } \\
\text { Nery Rev. } \\
\text { Enferm }\end{array}$ & $\begin{array}{l}\text { Охарактеризов } \\
\text { ать } \\
\text { подологический } \\
\text { профиль } \\
\text { пожилых } \\
\text { людей, } \\
\text { госпитализиров } \\
\text { анных в палаты } \\
\text { университетско } \\
\text { й больницы; } \\
\text { выявлять } \\
\text { потребности }\end{array}$ & Больница & $\begin{array}{l}\text { Укрепление } \\
\text { связей с } \\
\text { этими } \\
\text { пациентами с } \\
\text { диабетом, } \\
\text { чтобы они } \\
\text { приходили на } \\
\text { должность, } \\
\text { чтобы часто } \\
\text { выполнять } \\
\text { осмотры ног } \\
\text { Обучение и }\end{array}$ \\
\hline
\end{tabular}




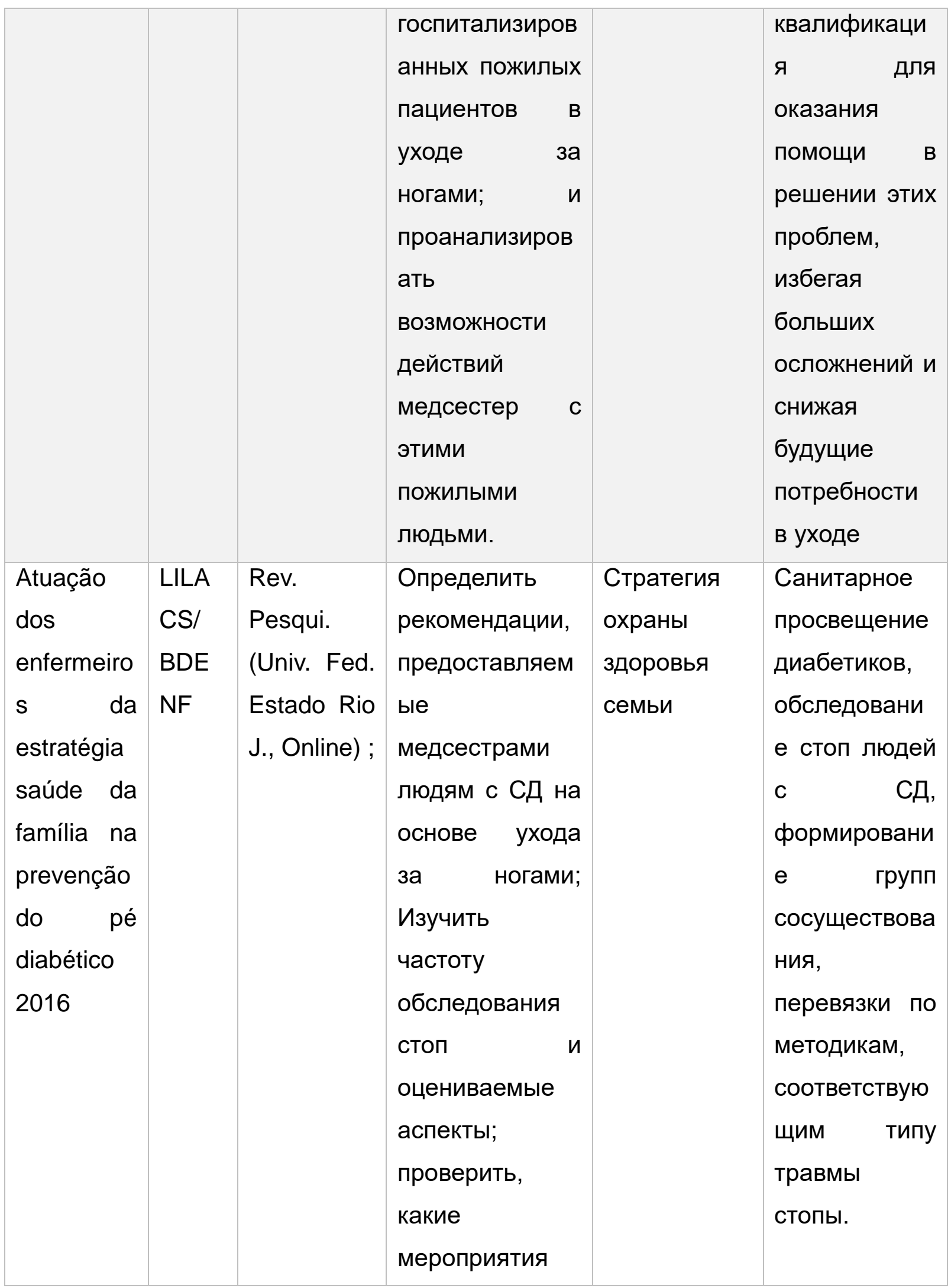




\begin{tabular}{|c|c|c|c|c|c|}
\hline & & & $\begin{array}{l}\text { по санитарному } \\
\text { просвещению } \\
\text { медсестры } \\
\text { выполняют для } \\
\text { людей с СД. }\end{array}$ & & \\
\hline $\begin{array}{l}\text { A } \\
\text { perspectiv } \\
\text { a da } \\
\text { vulnerabili } \\
\text { dade na } \\
\text { avaliação } \\
\text { do pé } \\
\text { diabético } \\
\text { sob a ótica } \\
\text { de } \\
\text { enfermeiro } \\
\text { s } \\
2016\end{array}$ & $\begin{array}{l}\text { BDE } \\
\text { NF }\end{array}$ & $\begin{array}{l}\text { Cogitare } \\
\text { enferm }\end{array}$ & $\begin{array}{l}\text { Запишите } \\
\text { социальные } \\
\text { детерминантны } \\
\text { е состояния } \\
\text { здоровья, } \\
\text { выявленные } \\
\text { медсестрами } \\
\text { как имеющие } \\
\text { отношение } \\
\text { установлению } \\
\text { уязвимостей } \\
\text { человека с } \\
\text { сахарный } \\
\text { диабет. }\end{array}$ & $\begin{array}{l}\text { Случайно } \\
\text { выбранные } \\
\text { медсестры в } \\
\text { Куритибе }\end{array}$ & $\begin{array}{l}\text { Стимулируйт } \\
\text { е диабетика } \\
\text { идти на } \\
\text { оценку } \\
\text { питания и } \\
\text { соблюдать } \\
\text { диету. }\end{array}$ \\
\hline
\end{tabular}

Источник: Автор.

В своих целях исследования упоминаются три вида ухода, выполняемого медсестрами для пациентов с диабетическая стопа: первый, который наиболее возник, основан на действиях, направленных на санитарное просвещение как фундаментальный принцип профилактики заболеваний и их осложнений, второй уход основан на методах оценки стоп у диабетиков как способ возникновения осложнений, а третий уход фокусируется на медсестрах как стимуляторе и мотиваторе. больные сахарным диабетом к уходу за собой ногами. Эти три меры предосторожности будут обсуждаться в их темах в соответствии с выбранными исследованиями.

RC: 105167

Доступно в:

https://www.nucleodoconhecimento.com.br/здравоохранение/диабетическая-стопа 


\section{1 ЗДОРОВЬЕ ОБРАЗОВАНИЯ КАК ФОРМА ПРОФИЛАКТИКИ}

Поэтому из санитарного просвещения пациент может понять причины, по которым процесс заживления ран протекает медленно, причины основных осложнений и особенно знания, связанные с профилактикой рисков. Медсестры должны быть в состоянии распознать потребности пациента и, таким образом, способствовать точной и безопасной сестринской диагностике, связанной с раной на ее стадии.

Scain; Franzen; Hirakata (2018) сообщают, что медсестры продолжают усилия по проведению санитарного просвещения пациентов, становясь настойчивыми и настойчивыми для продолжения образовательного процесса у пациентов с диабетической стопой, используют творческий подход к разработке образовательных технологий, таких как папки, видео, а также доступны для того, чтобы задавать вопросы о каком-то ненормальном состоянии с пациентом из технологий социальных сетей, таких как Whatsapp / телефон.

Camillo et al. (2016) упоминает, что концепция санитарного просвещения выходит за рамки приведения данных или даже устранения возникающих сомнений, авторы рассматривают санитарное просвещение как систематический, непрерывный и постоянный процесс, направленный на формирование и развитие критического сознания гражданина, через поиск коллективных решений пережитых проблем и их «реального участия» в осуществлении социального контроля.

Vargas et al. (2017) приводит санитарное просвещение в качестве одной из основных целей приписывания медсестер к уходу, авторы подчеркивают, что санитарное просвещение способствует более активной позиции пациента, демонстрируя, что пациент должен иметь уверенность в уходе за диабетическая стопа.

RC: 105167

Доступно в:

https://www.nucleodoconhecimento.com.br/здравоохранение/диабетическая-стопа 
Автономия и безопасность медицинской помощи были также отмечены в качестве результатов санитарного просвещения, проводимого медсестрами в исследовании Pereira et al. (2017), авторы сообщают, что санитарное просвещение становится основным механизмом профилактики заболеваний и их осложнений, в отношении диабетическая стопа санитарное просвещение способствует безопасности, доверию и автономии пациентов.

Демонстрация того, что санитарное просвещение является эффективным, была выявлена в описательном исследовании количественного подхода, в котором было показано, что санитарное просвещение дает пациентам теоретические знания о заболевании с уважением к культуре и убеждениям пациентов и что содействие образовательным процессам происходит не только вместе, но и индивидуально, устранение сомнений, которые пронизывают пациента во время консультации медсестры или даже в неформальном диалоге между пациентом и профессионалом (DE OLIVEIRA et al., 2016).

Но санитарное просвещение не только определяется как процесс ухода за пациентами, медсестры также должны быть внимательны к обучению и квалификации, что также можно считать медицинским образованием в более техническом плане. Silva; Santo и Chibante (2017) утверждает, что медсестры всегда должны быть обновлены к новым способам ухода за диабетическая стопа, поскольку процессы лечения все чаще изучаются в научной литературе и приносят инновации для заживления или даже постановки раны.

Поэтому санитарное просвещение, непрерывное образование и непрерывное образование являются фрормами ухода, которые медсестры используют для улучшения клинической картины пациентов с диабетическая стопа.

\section{2 МЕТОДЫ ОЦЕНКИ ДИАБЕТИЧЕСКОЙ СТОПЫ}

Научно-технические знания, приобретенные на этапах сестринского образования и в контексте непрерывного и постоянного образования, являются 
важными фракторами для лечения диабетическая стопа, поэтому медсестра должна искать знания для выполнения безопасных методов оценки для пациентов с диабетом в качестве метода профилактики и для пациентов с диабетическая стопа в качестве мер профилактики осложнений.

Arruda et al. (2019) утверждает, что фризическое обследование диабетических стоп - это процедуры, выполняемые медсестрами во избежание возможных осложнений, таких как: развитие язв и ампутаций нижних конечностей. Поэтому незнание этой методики вызывает более высокие показатели осложнений. Авторы отметили в другое время, что в дополнение к тому, что техника не используется из-за отсутствия знаний медсестры, условия труда также влияют на неэфрфективность метода оценки, эти условия называются авторами неадекватной инфраструктурой и спросом на чрезмерный уход.

Vargas et al. (2017) приводит в своем исследовании контекст, аналогичный ранее упомянутому исследованию, и добавляет, что медсестры нуждаются в большей подготовке в отношении методов оценки, связанных с диабетическая стопа, медсестры также сообщают, что руководство не предлагает материалы для выполнения этих методов и говорит о чрезмерных требованиях.

Pereira et al. (2017) считает, что должны быть предприняты конкретные действия для изменения системы ухода за пациентами с диабетическая стопа, эти действия должны быть связаны за пределами обследования стопы, представляя эффеективную коммуникацию и санитарное просвещение.

Leal et al. (2016) считает, что медсестры могут иметь незнание предмета из-за нескольких фракторов, и один из них указывается авторами как высокий спрос на уход. Это требование подразумевает физическое и психическое истощение профессионала, что обеспечивает нехватку времени на профессиональную квалификацию. В другом смысле авторы отмечают, что чрезмерный спрос на данную проблему дает профессионалу возможность освободить место для постоянного санитарного просвещения, в котором этот тип обучения 
предлагает трансформации в профессиональной практике на основе существующих проблем в процессе обучения их работе, чтобы отразить практику в их реальности.

Сестринское дело несет с собой функцию лечения заболеваний кожи и прилегающих к ней заболеваний. Это связано с тем, что медсестры имеют в своих атрибутах уход за пациентом и необходимость расширения этого ухода, связанного с заболеваниями, связанными с кожей (DA SILVA BRANDAO et al., 2016; SA et al., 2016).

\section{3 МЕДСЕСТРА-ПОСРЕДНИК ПО САМОУХОДУ ЗА ПАЦИЕНТАМИ С ДИАБЕТИЧЕСКАЯ СТОПА}

Говоря о заботе о себе, мы имеем в виду любое действие, вытекающее из повседневного акта человека. Что касается самообслуживания Arruda et al. (2019) сообщают, что пациенты с диабетическая стопа, как правило, оказывают большое экономическое, социальное, культурное, эмоциональное и биологическое воздействие, что способствует большей зависимости от других, чтобы помочь в повседневной жизнедеятельности и повлиять на их самообслуживание и качество жизни.

Scain; Franzen и Hirakata (2018) сообщают, что пациент должен быть осведомлен о выполнении своей собственной деятельности и что уход за собой должен быть непрерывным, одним из способов выполнения самообслуживания, упомянутых авторами, были: Гигиена ног; выбор подходящей обуви; избегайте ходьбы босиком и других.

Vargas et al. (2017) приносит в качестве самообслуживания поддержание гликемического контроля, активное участие пациентов в выполнении осмотров стоп, терапию, абсолютное ограничение употребления табака и напитков, питание, фризические упражнения, фризическую активность и другие фрормы, которые предусматривают ранее упомянутое исследование.

RC: 105167

Доступно в:

https://www.nucleodoconhecimento.com.br/здравоохранение/диабетическая-стопа 
Способ достижения того, чтобы пациент мог стремиться к самообслуживанию, приводится авторами Silva; Santo и Chibante (2017) как укрепление связей между пациентом и медицинским работником. Это усиление способствует безопасности и доверию пациента, что выполнение самообслуживания ног непрерывным и систематическим образом, тем ниже шансы риска осложнений.

Автономность и безопасность, демонстрируемые пациентами с диабетическая стопа, минимизируют повреждения и риски осложнений. Пациент, который участвует в лечении своего заболевания, стремится расширить свои знания до независимости других людей, формулируя в своей деятельности самообслуживание как форму мотивации и демонстрации способности перед лицом невзгод, которые связаны с процессом здоровья-болезни (DE OLIVEIRA et al., 2016).

Fátima Bento et al. (2016), пациенты с диабетическая стопа уже страдают стигматизацией от своего состояния, что затрудняет для них адекватный уход, потому что условия, которые предполагают дистанцирование от медицинского блока, трудности в мобилизации, мало знаний о болезни, допускают неадекватную помощь и эволюцию осложнений.

Однако Nascimento et al. (2016) упомянуть, что когда квалифицированная и гуманизированная помощь предоставляется посредством эфффективного поведения, с легким доступом к медицинским услугам, к которым все действия могут быть интегрированы на всех уровнях ухода, самообслуживания без риска осложнений.

\section{4. ВЫВОД}

Это исследование отразилось на заботе медсестер и профессионалов в выполнении ухода и ухода за пациентами с диабетическая стопа. Соответствующие исследования по уходу определили, что привело к реализации трех тем для обсуждения найденных результатов. 
Цель исследования направлена на то, чтобы подчеркнуть уход, оказываемый медсестрам пациентам с диабетическая стопа, подчеркивается, что особое внимание уделялось уходу за медсестрами, а не другими категориями сестринского дела. Исследования продемонстрировали санитарное просвещение как первую помощь, что не может быть опровергнуто, поскольку в литературе подчеркивается, что санитарное просвещение имеет первостепенное значение для профилактики заболеваний.

Другой тип ухода отражается на собственных знаниях профессионала о диабетическая стопа, о крайней необходимости и большой обеспокоенности в системе здравоохранения, поскольку статьи привели к размышлениям о том, что медсестры должны быть более квалифицированными, чтобы направлять уход с большим совершенством пациенту.

Важной заботой, также отмеченной исследованиями и направленной непосредственно на постоянное или непрерывное образование специалистов, являются методы фризического осмотра, в этом типе ухода медсестра должна быть в состоянии выполнять обследование диабетической стопы мудро и безопасно, а также поощрять пациентов чаще ходить на обследование.

Что касается ухода, связанного с собственным уходом за собой пациента, то было отражено, что гигиена стоп, гликемический контроль, постоянное наблюдение за осмотром стоп, использование соответствующей обуви и другие усиливают большую профилактику осложнений, среди которых ампутация конечностей.

Таким образом, делается вывод о том, что исследование выявило несколько форм ухода, предоставляемого медсестрами, и что все эти фрормы важны для непрерывности лечения, профилактики и осложнений, однако медсестра должна быть профессионалом, который ценит качество своего ухода на основе теоретических концепций, которые приводят к частому обучению. 


\section{ИСПОЛЬЗОВАННАЯ ЛИТЕРАТУРА}

AMERICAN DIABETES ASSOCIATION. Standards of medical care in diabetes. Diabetes Care, v. 40, n. suppl 1, p. s1-s128, 2017.

ARRUDA, Cecilia et al. Tecnologia educativa para cuidados e prevenção do pé diabético/Educational technology for care and prevention of diabetic foot ulcers. Ciência, Cuidado e Saúde, v. 20, 2021.

ARRUDA, Luana Savana Nascimento de Sousa et al. Conhecimento do enfermeiro acerca dos cuidados com o pé diabético. Rev. enferm. UFPE on line, p. [1-8], 2019.

ASCHNER M, Pablo et al. Clinical practice guideline for the prevention, early detection, diagnosis, management and follow up of type 2 diabetes mellitus in adults. Colomb. Med., Cali, v. 47, n. 2, p. 109-130, junho. 2016.

CAMILLO, Bibiana Schultz et al. Ações de educação em saúde na atenção primária a gestantes e puérperas: revisão integrativa. Revista de enfermagem UFPE on line-ISSN: 1981-8963, v. 10, n. 6, p. 4894-4901, 2016.

CUBAS, Marcia Regina et al. Pé diabético: orientações e conhecimento sobre cuidados preventivos. Fisioterapia em movimento, v. 26, n. 3, 2017.

DE FÁTIMA BENTO, Leandra et al. A perspectiva da vulnerabilidade na avaliação do pé diabético sob a ótica de enfermeiros. Cogitare Enfermagem, v. 21, n. 1, 2016.

DE OLIVEIRA, Patrícia Simplício et al. Atuação dos enfermeiros da Estratégia Saúde da Família na prevenção do pé diabético Practice nurse family health strategy in the prevention of diabetic foot. Revista de Pesquisa Cuidado é Fundamental Online, v. 8, n. 3, p. 4841-4849, 2016.

DE SOUZA MENDONÇA, Sarah; MORAIS, Juliana de Sant'Anna; DE MOURA, Maria Catarina Gomes Gadelha. Proposta de um protocolo de avaliação 
fisioterapêutica para os pés de diabéticos. Fisioterapia em Movimento, v. 24, n. 2, 2017.

FELIX, Lidiany Galdino et al. Conhecimento de enfermeiros da atenção primária antes e após intervenção educativa sobre pé diabético. Revista Gaúcha de Enfermagem, v. 42, 2021.

LEAL, Maria do Carmo et al. Atenção ao pré-natal e parto em mulheres usuárias do sistema público de saúde residentes na Amazônia Legal e no Nordeste, Brasil 2010. Rev. Bras. Saude Mater. Infant. Recife, v. 15, n. 1, p. 91-104, Mar. Available from \&lt; http://www.scielo.br/scielo.php?script=sci_arttext\&amp;pid=S151938292015000100091\&amp; Ing=en\&amp;nrm=iso\&gt;.

MENDES, Karina Dal Sasso; SILVEIRA, Renata Cristina de Campos Pereira; GALVÃO, Cristina Maria. Uso de gerenciador de referências bibliográficas na seleção dos estudos primários em revisão integrativa. Texto \& ContextoEnfermagem, v. 28, 2019.

MINAYO, Maria Cecília de Souza. Análise qualitativa: teoria, passos e fidedignidade. Ciência \& saúde coletiva, v. 17, p. 621-626, 2012.

MUZY, Jéssica et al. Prevalência de diabetes mellitus e suas complicações e caracterização das lacunas na atenção à saúde a partir da triangulação de pesquisas. Cadernos de Saúde Pública, v. 37, 2021.

NASCIMENTO, Vagner Ferreira do et al. Percepção de puérperas sobre as primeiras consultas de pré-natal no interior de Mato Grosso. Rev. enferm. UFPI, v.5, n. 1, p. 46-51, 2016.

ORGANIZAÇÃO MUNDIAL DE SAÚDE. Definition, diagnosis and classification of diabetes Mellitus and its complications. Geneva: OMS, 1999. Disponível em: https://apps.who.int/iris/bitstream/handle/10665/66040/WHO_NCD_NCS_99.2.pdf?s equence $=1$ \&isAllowed $=\mathrm{y}$

RC: 105167 
PEREIRA, Laiane de Fátima et al. Ações do enfermeiro na prevenção do pé diabético: o olhar da pessoa com diabetes mellitus. Rev. pesqui. cuid. fundam. (Online), p. 1008-1014, 2017.

SCAIN, Suzana Fiore; FRANZEN, Elenara; HIRAKATA, Vânia Naomi. Riscos associados à mortalidade em pacientes atendidos em um programa de prevenção do pé diabético. Revista Gaúcha de Enfermagem, v. 39, 2018.

SILVA, Caline Oliveira da. Análise da qualidade de vida em indivíduos com Diabetes Mellitus Tipo 1. 2017. 34 f. Trabalho de conclusão de curso (Bacharelado em Farmácia) -Universidade de Brasília, Brasília, 2017. Disponível em: https://bdm.unb.br/handle/10483/19301

SILVA, Joziane Santos da; SANTO, Fátima Helena do Espírito; CHIBANTE, Carla Lube de Pinho. Alterações nos pés do idoso hospitalizado: um olhar cuidadoso da enfermagem. Escola Anna Nery, v. 21, 2017.

SOCIEDADE BRASILEIRA DE DIABETES. Tratamento e acompanhamento do diabetes Mellitus: Diretrizes da Sociedade Brasileira de Diabetes. 3.ed. Itapevi, SP: A. Araújo Silva Farmacêutica; 2017/2018. Disponível em: http://www.diabetes.org.br/ profissionais/images/2017/diretrizes/diretrizes-sbd-20172018.pdf.

VARGAS, Caroline Porcelis et al. Condutas dos enfermeiros da atenção primária no cuidado a pessoas com pé diabético. Rev. enferm. UFPE on line, p. 4535-4545, 2017.

Представлено: Октябрь 2021 года.

Утвержден: Декабрь 2021 года. 